\title{
Effects of Aloe Sterol Supplementation on Skin Elasticity, Hydration, and Collagen Score: A 12-Week Double-Blind, Randomized, Controlled Trial
}

\author{
Miyuki Tanaka ${ }^{a}$ Yuki Yamamoto $^{\mathrm{b}}$ Eriko Misawa $^{\mathrm{a}}$ Kazumi Nabeshima ${ }^{\mathrm{a}}$ \\ Marie Saito $^{a}$ Koji Yamauchi ${ }^{a} \quad$ Fumiaki Abe $^{a} \quad$ Fukumi Furukawa $^{\text {b }}$ \\ ${ }^{a}$ Functional Food Ingredients Department, Food Ingredients and Technology Institute, Morinaga Milk Industry Co.,

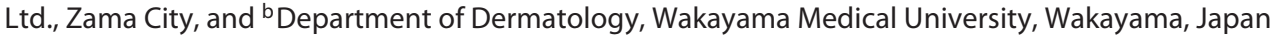

\section{Keywords}

Aloe vera $\cdot$ Aloe sterol · Skin moisture $\cdot$ Skin elasticity ·

Collagen score

\section{Abstract}

Background/Aims: Our previous study confirmed that Aloe sterol stimulates collagen and hyaluronic acid production in human dermal fibroblasts. This study aims to investigate whether Aloe sterol intake affects skin conditions. Methods: We performed a 12-week, randomized, double-blind, placebo-controlled study to evaluate the effects of oral Aloe sterol supplementation on skin elasticity, hydration, and the collagen score in 64 healthy women (age range 30-59 years; average 44.3 years) who were randomly assigned to receive either a placebo or an Aloe sterol-supplemented yogurt. Skin parameters were measured and ultrasound analysis of the forearm was performed. Results: ANCOVA revealed statistical differences in skin moisture, transepidermal water loss, skin elasticity, and collagen score between the Aloe sterol and placebo groups. The gross elasticity (R2), net elasticity (R5), and biological elasticity (R7) scores of the Aloe sterol group significantly increased with time. In addition, skin fa- tigue area F3, which is known to decrease with age and fatigue, also increased with Aloe sterol intake. Ultrasound echogenicity revealed that the collagen content in the dermis increased with Aloe sterol intake. Conclusion: The results suggest that continued Aloe sterol ingestion contributes to maintaining healthy skin.

(c) 2017 S. Karger AG, Basel

\section{Introduction}

Dry skin is a common problem. It has an increasing incidence and severity with age, which is characterized by itching, burning, stinging, and a feeling of tightness that affects the quality of life [1]. Therefore, prevention of transepidermal water loss (TEWL) to maintain skin moisture is crucial to skin health.

The 2 types of fibers in the dermis are mostly collagen $(97.5 \%)$ and elastin (2.5\%) [2]. Collagen fibers maintain the 3-dimensional structure of the skin, whereas elastin fibers form a 3-dimensional network between the collagen fibers. Thus, damage and loss of collagen and elastin impair the contractile properties of the skin. In the der-

\section{KARGER}

E-Mail karger@karger.com

www.karger.com/spp (c) 2017 S. Karger AG, Base

1660-5527/17/0296-0309\$39.50/0
Miyuki Tanaka

Functional Food Research Department, Food Science and Technology Institute Morinaga Milk Industry Co., Ltd., 1-83 Higashihara 5-chome

Zama City, Kanagawa 252-8583 (Japan)

E-Mail m_tanaka@morinagamilk.co.jp 
mis, heterotypic collagen fibrils contain mainly type I and type III collagen. The major function of type III collagen is associated with fibrogenesis of type I collagen [3]. Varani et al. [4] reported that reduced collagen synthesis in chronologically aged skin reflects at least 2 different underlying mechanisms: aging of cellular fibroblasts and reduced mechanical stimulation.

Age-related loss of cutaneous elasticity is associated with an increased incidence of both skin tears and pressure ulcers [5]. Ultrasonography is often used for noninvasive visualization and quantification of age-related dermal changes. Koyano et al. [6] reported that the number of ultrasonographic subepidermal low-echogenic bands (LEB) is correlated with skin tears. They also indicated that the abundance of type IV collagen in the dermis was statistically lower in patients with skin tears than in those without. Therefore, a reduction in dermis collagen density is associated with skin fragility.

Aloe vera (A. barbadensis Miller) gel is obtained from the mesophyll that contains polysaccharides, amino acids, lipids, plant sterols, tannins, and enzymes and has been used as herbal medicine $[7,8]$. Aloe sterol is included in A. vera gel and possess a unique efficacy [9]. Structurally, Aloe sterol falls into 2 groups of compounds, i.e., the lophenol (lophenol, 24-methyl-lophenol, 24-ethyl-lophenol) and cycloartane (cycloartanol and 24-methylene-cycloartanol) groups. Aloe sterol has the ability to activate the peroxisome proliferator-activated receptors (PPAR) of natural or pharmaceutical specific ligands [10]. PPAR regulate the expression of genes that are mostly involved in lipid and carbohydrate metabolism, energy production, and anti-inflammation activities [11]. Barlaka et al. [12] reported that a novel connection between PPAR signaling and downregulation of matrix metalloproteinases (MMP) in cardiac myocytes may be involved in the management of oxidative stress-induced cardiac dysfunction. Our recent study demonstrated that Aloe sterol significantly prevented an increase in the total protein expression of MMP-2 (active and pro) and MMP-9 (active and pro) in ultraviolet B (UVB)-irradiated mice [13].

The whole leaf and peel of $A$. vera are considered to contain anthraquinones, which generate reactive oxygen species in the presence of UVA light. The reactive oxygen species generated by UVA are associated with photodamage and photoaging of human skin [14]. A. vera gel is the leaf mesophyll, which does not include an influential quantity of anthraquinones.

The application of $A$. vera has also been shown to shorten the recovery period and improve the skin health of rats with diabetes $[15,16]$. We and other groups have reported that intake of $A$. vera gel powder improves facial wrinkles $[17,18]$.

In this study, we examined the influence of Aloe sterol intake on skin conditions (i.e., hydration, TEWL, and elasticity) and conducted an ultrasonographic imaging analysis of the dermis.

\section{Materials and Methods}

\section{Trial Registration}

This trial was registered in the UMIN Clinical Trial Registry on September 15, 2015 (UMIN000019019).

\section{Test Samples}

For this study, 2 drinkable yogurts were produced under established controlled conditions and packaged in small white plastic containers. The Aloe sterol yogurt contained $40 \mu \mathrm{g}$ of Aloe sterol per $100 \mathrm{~g}$. The nutrient composition per $100 \mathrm{~g}$ of the yogurt was as follows: energy, $45 \mathrm{kcal}$; fat, $0.3 \mathrm{~g}$; protein, $3 \mathrm{~g}$; carbohydrates, $9.4 \mathrm{~g}$; and $A$. vera gel powder, $0.5 \mathrm{~g}$. The $A$. vera gel powder was prepared by drying the mesophyll of $A$. vera plants. In the placebo yogurt, the $A$. vera gel powder was replaced with guar gum.

\section{Study Design}

This study was conducted as a monocentric, double-blinded, randomized, placebo-controlled, supplementation study on the effects of Aloe sterol on skin elasticity, hydration, TEWL, and the collagen score after 12 weeks of daily Aloe sterol intake. This study was carried out from August 2015 to December 2015, which was from summer to winter in Japan.

\section{Subjects}

A total of 64 healthy adult Japanese women (age 30-59 years) were randomly assigned to the placebo $(n=32)$ or Aloe sterol $(n=$ 32) group. Each participant was identified by a code that was randomly selected using a computer-generated permutation procedure. The codes were sequentially allocated to the participants in the order in which they were enrolled. After all of the measurements had been completed, the randomization codes were disclosed to the investigators. The study participants, investigators, staff members, and laboratory technicians were blinded to the group assignment.

\section{Inclusion Criteria}

The inclusion criterion was: healthy females ranging in age from 30 to 59 years.

\section{Exclusion Criteria}

The exclusion criteria were: individuals who regularly use cosmetics or consume food that adversely affects the skin's condition; those who use cosmetics and creams, except for sunscreen, on their arms; those whose arms have a skin abnormality that requires treatment; those having allergic diseases with sleep deprivation or a sleep disorder; those with a skin disease; those who excessively consume alcohol; current smokers (smoking over 20 cigarettes/ day); those with a history of serious skin disease, liver disease, kid- 
Table 1. Demographic and baseline characteristics

\begin{tabular}{lllll}
\hline & Group & Mean & SD & $p$ value \\
\hline Age, years & Aloe sterol & 44.1 & 6.9 & 0.844 \\
& Placebo & 44.5 & 7.0 & \\
\hline BMI & Aloe sterol & 20.2 & 2.8 & 0.397 \\
& Placebo & 20.9 & 3.8 & \\
\hline Blood pressure, mm Hg & & & & \\
Systolic & Aloe sterol & 109.6 & 12.7 & 0.883 \\
& Placebo & 110.1 & 14.3 & \\
\multicolumn{1}{c}{ Diastolic } & Aloe sterol & 70.7 & 9.8 & 0.850 \\
& Placebo & 70.2 & 8.6 & \\
\hline Skin hydration, AU & Aloe sterol & 24.3 & 3.3 & 0.652 \\
& Placebo & 25.9 & 5.0 & \\
\hline TEWL, g/h/m ${ }^{2}$ & Aloe sterol & 5.75 & 1.17 & 0.832 \\
& Placebo & 5.58 & 1.69 & \\
\hline F3, skin fatigue area & Aloe sterol & 7.476 & 0.740 & 0.438 \\
& Placebo & 7.637 & 0.899 & \\
\hline
\end{tabular}

AU, arbitrary units; TEWL, transepidermal water loss. the following parameters: R2 (gross elasticity), R5 (net elasticity), and R7 (biological elasticity). Furthermore, the parameter F3 (skin fatigue area) was included as a continuous viscoelastic measurement using Cutometer software. Ultrasonography evaluations were performed using the Dermalab skin analysis system (Cortex Technology ApS, Hadsund, Denmark). The intensity of the reflected echoes was evaluated using a microprocessor and visualized as a colored image. The color scale of echogenicity was as follows: white $>$ yellow $>$ red $>$ green $>$ blue $>$ black. In each image, the number of ultrasonographic LEB and the collagen score were measured using image analysis software (Cortex Technology ApS).

\section{Statistical Analysis}

All data were analyzed based on the intention-to-treat principle. Skin parameters were analyzed using analysis of covariance with treatment effect and baseline skin parameters as covariates. Least-squares (LS) means of the Aloe sterol and placebo groups and the corresponding 95\% CI were estimated. The difference between means before and after treatment was assessed using a $t$ test for paired samples. Differences with a $p$ value $<0.05$ were considered statistically significant.

\section{Results}

ney damage, heart disease, lung disease, endocrine disease, or metabolic disease; those with a history of drug allergy or a serious food allergy; those who are pregnant or breast-feeding or have planned a pregnancy during the study period; those with simultaneous participation in other clinical studies; those with chronic constipation (defecation less than 3 times/week) in the past 3 months; and those judged inappropriate for this study based on subject background, physical findings, or medical examination.

\section{Measurement of Skin Parameters}

The effectiveness of Aloe sterol on skin moisture, TEWL, skin elasticity, and the collagen score was compared between the 2 groups. The test area was the inner side of one forearm. The skin parameters were examined and ultrasound imaging was performed using noninvasive methods at weeks $0,4,8$, and 12 of the treatment period. Measurements were performed under standard conditions of room temperature $\left(20-22^{\circ} \mathrm{C}\right)$ and humidity $(45-$ $55 \%)$. Participants were acclimated to the room conditions for at least $20 \mathrm{~min}$ before the examination. Analysis of each skin parameter was performed 5 times at each time point. A Corneometer CM 825 device (Courage + Khazaka Electronic GmbH, Cologne, Germany) was used to determine the skin hydration level. A hand-held Tewameter TM300 device (Courage + Khazaka Electronic $\mathrm{GmbH}$ ) was used to measure TEWL levels. Skin elasticity was determined using a Cutometer MPA 580 device (Courage + Khazaka Electronic $\mathrm{GmbH})$. Measurements were taken using a Cutometer MPA 580 device with a 4-mm-diameter opening suction probe at 5 different locations on the inner forearm. A constant vacuum of 300 mbar was applied to the skin for $2 \mathrm{~s}$, followed by a relaxation time of $2 \mathrm{~s}$. To study F3, ten repetitions of the measurement cycle were performed. F3 is the area within the envelope curve which is determined between the second and last suction cycles. Viscoelastic measurements were evaluated according to

\section{Subject Demographics}

A total of 64 healthy women were initially enrolled into this study and none were excluded. Therefore, all 64 women were randomized to receive Aloe sterol or placebo in a double-blind manner. An intention-to-treat analysis was performed for all participants $(n=64)$. The baseline characteristics of the 2 groups were comparable (Table 1 ). Furthermore, there were no significant differences in skin parameters between the 2 groups. No significant treatment-related adverse events were reported with respect to blood, lipid, or biochemical parameters during the 12week study period (data not shown).

\section{Skin Hydration and TEWL (Barrier Integrity)}

TEWL levels were higher during the test period than at baseline in both groups (Fig. 1a). Figure 1 shows the skin hydration (epidermal hydration) parameters during the 12 -week treatment period. The forearm skin hydration levels of the Aloe sterol group were significantly greater at 4,8 , and 12 weeks $(26.8 \pm 0.7,26.7 \pm 0.8$, and $26.4 \pm 1.0$, respectively) than at baseline $(24.3 \pm 0.6)$. In contrast, the skin hydration levels in the placebo group significantly decreased in a time-dependent manner during the test period. After 12 weeks, the skin hydration level of the placebo group was $76 \%$ of the baseline value. Next, we analyzed the differences in skin hydration and TEWL values between the 2 groups using analysis of co- 
Fig. 1. Transepidermal water loss (TEWL) (a) and skin hydration changes (b) during the treatment period. Data are expressed as means \pm SEM $(n=32) .{ }^{*} p<0.05,{ }^{* *} p<$ 0.001 vs. baseline values. ${ }^{\#} p<0.05,{ }^{\# \#} p<$ 0.001 vs. placebo group values.
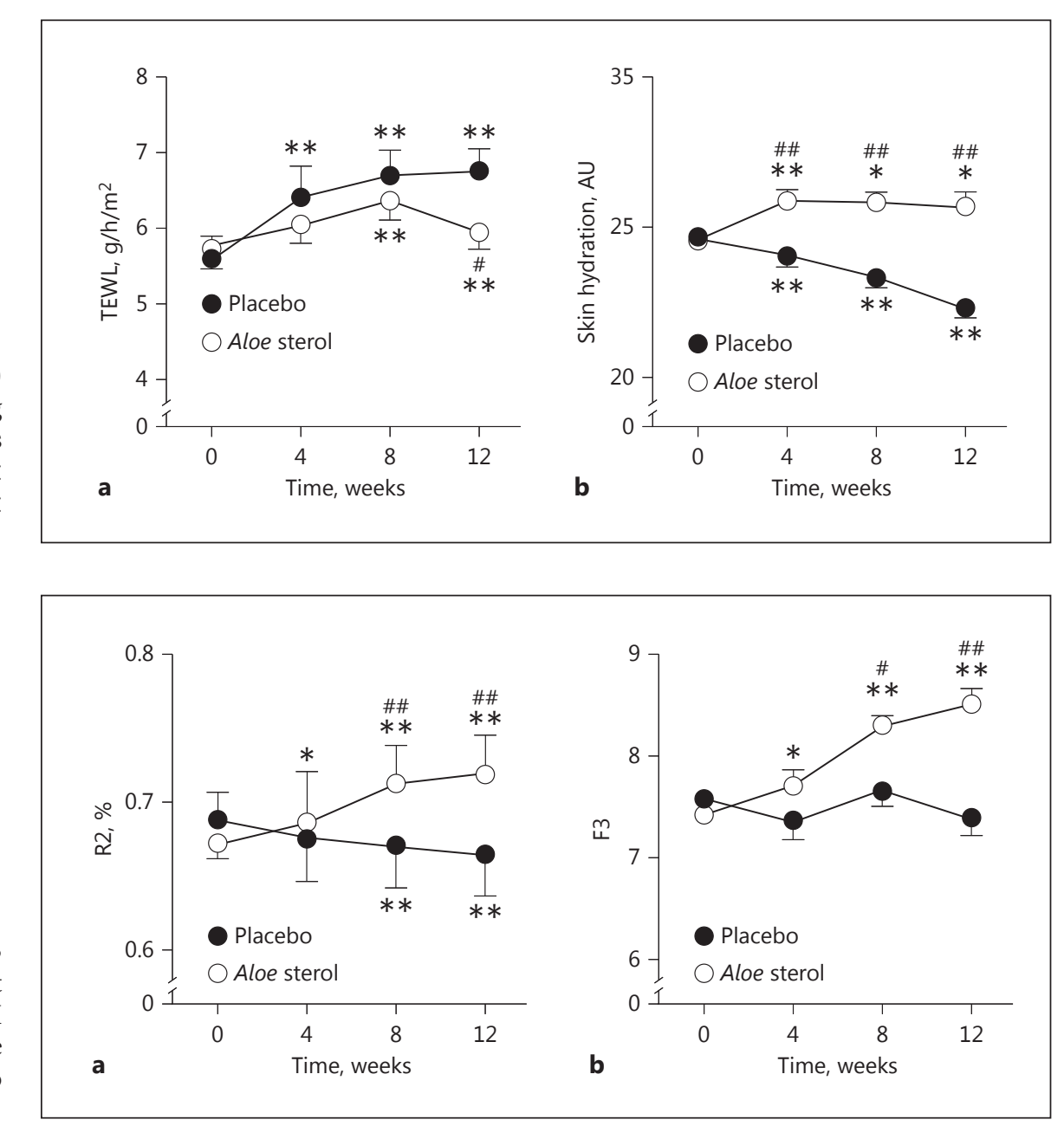

Fig. 2. R2 (skin gross elasticity) (a) and F3 (skin fatigue area) (b) during the treatment period. Data are expressed as means \pm SEM $(n=32) .{ }^{*} p<0.05,{ }^{* *} p<0.001$ vs. baseline values. ${ }^{\#} p<0.05,{ }^{\# \#} p<0.001$ vs. placebo group values. variance (Table 2). The LS means of skin hydration at 4 , 8 , and 12 weeks were statistically greater in the Aloe sterol group than in the placebo group. The LS means of TEWL at 4 and 12 weeks were statistically lower in the Aloe sterol group than in the placebo group.

\section{Skin Elasticity}

In the Aloe sterol group, the skin gross elasticity R2 parameters at baseline $(0.773 \pm 0.006)$ increased at 4,8 , and 12 weeks $(0.787 \pm 0.006,0.814 \pm 0.005$, and $0.820 \pm$ 0.005 , respectively). In contrast, the $\mathrm{R} 2$ parameters of the placebo group were lower at 8 and 12 weeks $(0.771 \pm 0.005$ and $0.765 \pm 0.005$, respectively) compared to the baseline value $(0.789 \pm 0.005$; Fig. 2 a). The oral placebo yogurt did not affect skin fatigue (F3 parameter; Fig. 2b). In contrast, the F3 values of the Aloe sterol group continued to increase throughout the treatment period. After 12 weeks of Aloe sterol yogurt intake, the amount of F3 was 114\% of the baseline value. Moreover, significant differences were observed in the skin elasticity parameters R2, R5, R7, and F3 between the groups (Table 3 ).

\section{Ultrasound Echogenicity}

Figure 3 presents typical changes in the ultrasound images of 6 participants ( 3 from each group) before and after 8 and 12 weeks of treatment with the Aloe sterol supplement or placebo. As shown, there were expansions of high-intensity echogenicity regions (i.e., high collagen score regions) in the images of the Aloe sterol group. In the placebo group images, some regions with intensities weaker than that at week 0 were observed.

We observed an increase in the amount of LEB at 8 and 12 weeks in both groups (Fig. 4a). The collagen score was reduced to $76 \%$ after 12 weeks of the placebo diet compared to baseline (Fig. 4b). In contrast, the collagen scores of the Aloe sterol group were significantly increased at 4, 
Table 2. Comparison of TEWL and skin hydration values between the 2 groups

\begin{tabular}{|c|c|c|c|c|c|c|}
\hline Parameter & Group & Week & LS mean & $\mathrm{SD}$ & $95 \% \mathrm{CI}$ & $p$ value $^{1}$ \\
\hline \multirow{5}{*}{ TEWL, g/h/m $\mathrm{m}^{2}$} & Aloe sterol & 4 & 5.92 & 0.18 & $5.56-6.28$ & 0.039 \\
\hline & Placebo & & 6.46 & 0.18 & $6.10-6.82$ & \\
\hline & Aloe sterol & 8 & 6.31 & 0.17 & $5.96-6.66$ & 0.134 \\
\hline & Placebo & & 6.68 & 0.17 & $6.34-7.01$ & \\
\hline & Aloe sterol & 12 & 5.86 & 0.19 & $5.48-6.23$ & 0.001 \\
\hline \multirow{5}{*}{ Skin hydration, AU } & Placebo & & 22.72 & 0.53 & $21.66-23.79$ & \\
\hline & Aloe sterol & 8 & 26.99 & 0.63 & $25.73-28.26$ & 0.000 \\
\hline & Placebo & & 21.50 & 0.63 & $20.24-22.77$ & \\
\hline & Aloe sterol & 12 & 26.64 & 0.73 & $25.17-28.11$ & 0.000 \\
\hline & Placebo & & 19.48 & 0.73 & $18.02-20.95$ & \\
\hline
\end{tabular}

AU, arbitrary units; TEWL, transepidermal water loss; LS, least-squares. $p<0.05$ was considered statistically significant.

${ }^{1}$ Analyzed using ANCOVA.

8 , and 12 weeks $(58.8 \pm 1.1,57.5 \pm 1.0$, and $59.1 \pm 1.5$, respectively) compared to baseline ( $54.8 \pm 1.6$; Fig. $4 \mathrm{~b})$.

The results of the covariance analysis of the collagen score are shown in Table 4 . The LS means of the collagen scores at 4, 8, and 12 weeks were significantly higher in the Aloe sterol group than in the placebo group. There was no statistical difference in LEB abundance between the Aloe sterol and placebo groups (data not shown).

\section{Discussion}

Maintenance of epidermal barrier function and skin moisture is crucial for skin health [19]. Compromise of the skin barrier function and humidity retention can lead to onset of a disease or itching, thereby reducing the quality of life $[20,21]$. Aloe sterol intake induced a significant increase in skin hydration (Table 2). Our previous study suggested that Aloe sterol stimulates hyaluronic acid production and hyaluronic acid synthesis in human dermal fibroblasts [17]. In addition, we confirmed that the hyaluronic acid content of the dermis of mice treated with oral Aloe sterol was higher than that of control mice irradiated with UVB [13]. In this study, we observed a reduction in skin moisture and an increase in TEWL levels in the placebo group in a time-dependent manner (Fig. 1a). The atmospheric humidity gradually decreased because of the seasonal change in Japan during the study period. Therefore, the observed reduction in skin moisture and the increase in TEWL levels observed in the pla-
Table 3. Comparison of skin elasticity parameters (R2, R5, R7, and F3) between the 2 groups

\begin{tabular}{|c|c|c|c|c|c|c|}
\hline & Group & Week & $\begin{array}{l}\text { LS } \\
\text { mean }\end{array}$ & $\mathrm{SD}$ & $95 \% \mathrm{CI}$ & $\begin{array}{l}p \\
\text { value }^{1}\end{array}$ \\
\hline \multirow[t]{5}{*}{$\mathrm{R} 2$} & Aloe sterol & 4 & 0.792 & 0.004 & $0.784-0.800$ & 0.001 \\
\hline & Placebo & & 0.772 & 04 & $764-0.780$ & \\
\hline & $\begin{array}{l}A \\
\mathrm{D}\end{array}$ & 8 & $f$ & & & \\
\hline & Aloe sterol & 12 & 0.822 & 0.005 & $0.813-0.831$ & 0.000 \\
\hline & Placebo & & 0.763 & 0.005 & $0.753-0.772$ & \\
\hline \multirow[t]{6}{*}{ R5 } & Aloe sterol & 4 & 0.718 & 0.008 & $0.702-0.733$ & 0.226 \\
\hline & Placebo & & 0.704 & 0.008 & $0.689-0.719$ & \\
\hline & Aloe sterol & 8 & 0.776 & 0.008 & $0.759-0.792$ & 0.000 \\
\hline & Placebo & & 0.689 & 0.008 & $0.673-0.706$ & \\
\hline & Aloe sterol & 12 & 0.785 & 0.010 & $0.764-0.806$ & 0.000 \\
\hline & Placebo & & 0.691 & 0.010 & $0.670-0.712$ & \\
\hline \multirow[t]{6}{*}{ R7 } & Aloe & 4 & 0.516 & 0.005 & $0.507-0.525$ & 0.027 \\
\hline & Placebo & & 0.501 & 0.005 & $0.492-0.510$ & \\
\hline & Aloe sterol & 8 & 0.558 & 0.006 & $0.546-0.569$ & 0.000 \\
\hline & Placebo & & 0.496 & 0.006 & $0.484-0.508$ & \\
\hline & Aloe sterol & 12 & 0.554 & 0.006 & $0.542-0.566$ & 0.000 \\
\hline & Placebo & & 0.494 & 0.006 & $0.482-0.506$ & \\
\hline \multirow[t]{6}{*}{ F3 } & Aloe sterol & 4 & 7.822 & 0.109 & $7.605-8.040$ & 0.003 \\
\hline & Placebo & & 7.349 & 0.109 & $7.132-7.566$ & \\
\hline & Aloe sterol & 8 & 8.361 & 0.111 & $8.139-8.584$ & 0.000 \\
\hline & Placebo & & 7.666 & 0.111 & $7.444-7.888$ & \\
\hline & Aloe sterol & 12 & 8.586 & 0.127 & $8.332-8.40$ & 0.000 \\
\hline & Placebo & & 7.393 & 0.127 & $7.139-7.646$ & \\
\hline
\end{tabular}

LS, least-squares. $p<0.05$ was considered statistically significant. ${ }^{1}$ Analyzed using ANCOVA. 
Fig. 3. Ultrasound skin images of in collagen content after 8 and 12 weeks of ingestion of the placebo (a) or Aloe sterol-supplemented yogurt (b). E, epidermal; D, dermis. Representative images of 3 subjects from each group are shown.

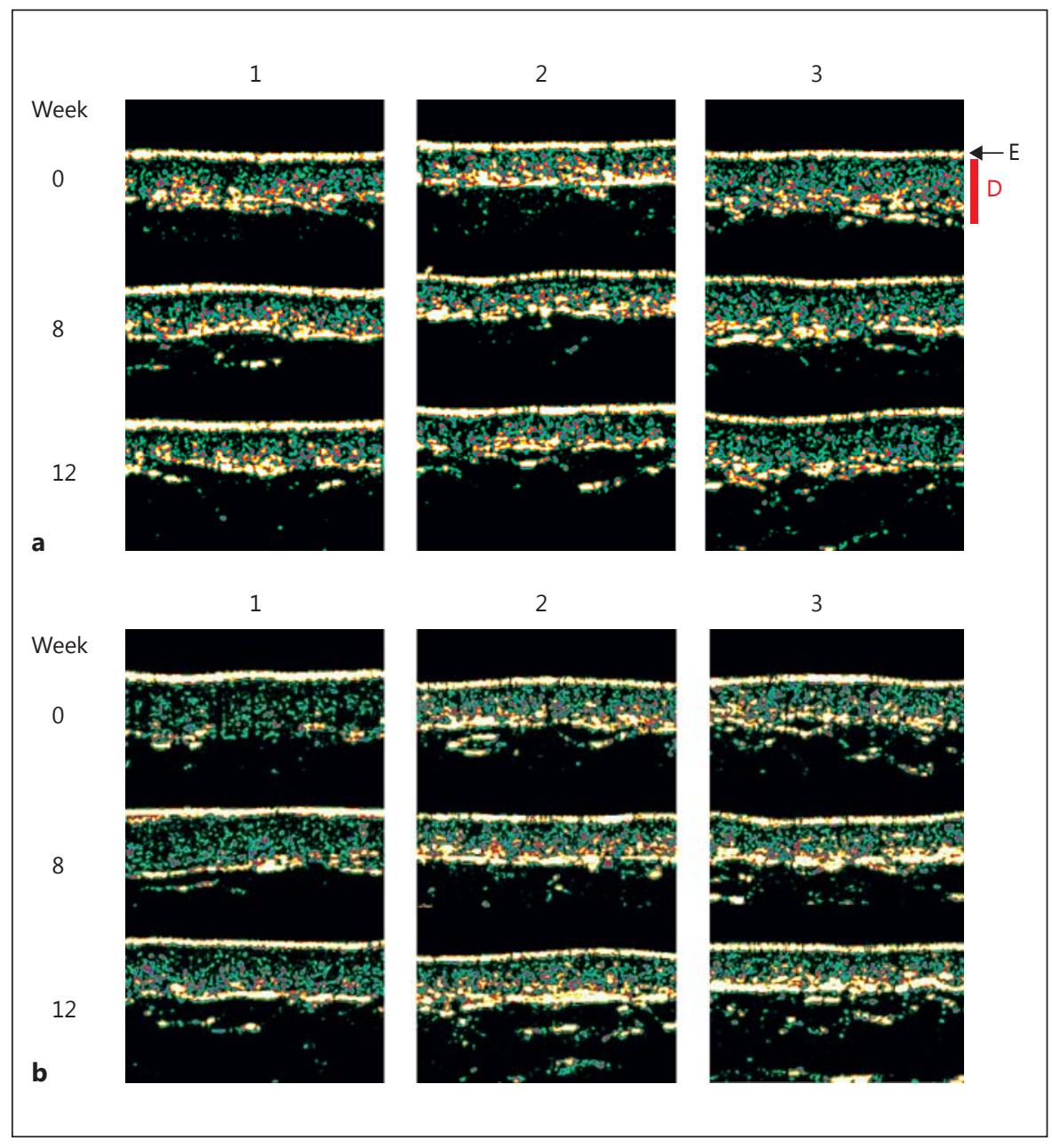

Table 4. Comparison of collagen scores between groups

\begin{tabular}{lccccc}
\hline Group & Week & $\begin{array}{l}\text { LS } \\
\text { mean }\end{array}$ & SD & $95 \%$ CI & $\begin{array}{l}p \\
\text { value }^{1}\end{array}$ \\
\hline $\begin{array}{l}\text { Aloe sterol } \\
\text { Placebo }\end{array}$ & 4 & 59.34 & 0.70 & $57.95-60.73$ & 0.000 \\
\hline $\begin{array}{l}\text { Aloe sterol } \\
\text { Placebo }\end{array}$ & 8 & 52.97 & 0.70 & $51.57-54.36$ & \\
\hline $\begin{array}{l}\text { Aloe sterol } \\
\text { Placebo }\end{array}$ & 12 & 58.03 & 0.83 & $56.37-59.69$ & 0.000 \\
\hline
\end{tabular}

LS, least-squares. $p<0.05$ was considered statistically significant. ${ }^{1}$ Analyzed using ANCOVA.

cebo group might have resulted from external environmental conditions, particularly reduced humidity. The TEWL levels at 4 and 12 weeks were significantly lower in the Aloe sterol group than in the placebo group. These results suggest that Aloe sterol intake contributed to the improvement in skin barrier function and the subsequent maintenance of skin moisture. However, it is difficult to explain the increase in skin hydration in the Aloe sterol group only based on the change in TEWL. We confirmed that intake of Aloe sterol increases the level of both skin hydration and hyaluronic acid synthetase in hairless mice [13]. Therefore, Aloe sterol may increase the level of skin moisture through the promotion of hyaluronic acid composition. Conversely, the TEWL level of this subject indicated a good skin barrier function. Thus, an additional experiment using an appropriate subject with a low TEWL level reduced by nicotinate exposure is necessary to investigate the influence of Aloe sterol on TEWL.

The elastic parameters of the skin decrease during chronological aging and photoaging [22, 23]. Dobrev [24] reported that, when examining skin mechanical properties with a Cutometer, the R2 and R7 parameters should 
Fig. 4. Low echogenic bands (LEB) (a) and collagen scores (b) during the treatment period. Data are expressed as means \pm SEM $(n=32){ }^{*} p<0.05,{ }^{* *} p<0.001$ vs. baseline values. ${ }^{\#} p<0.05,{ }^{\# \#} p<0.001$ vs. placebo group values.

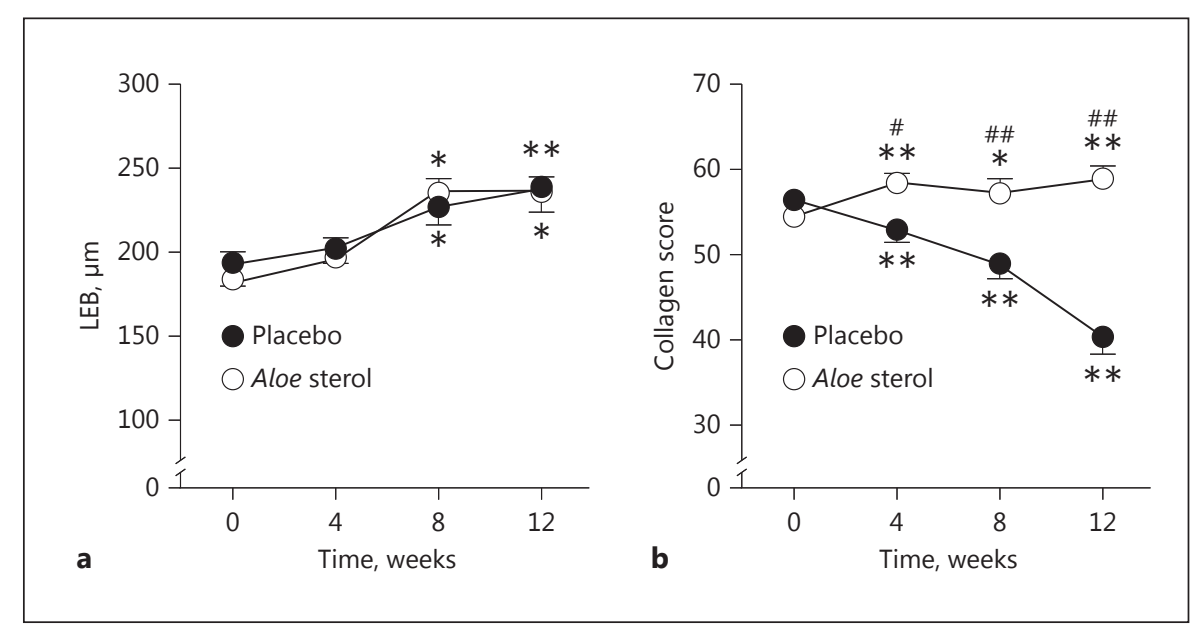

be measured. Ryu et al. [25] showed that skin elasticity measurement is useful for quantitative evaluation of agerelated changes, and age was negatively correlated with $\mathrm{R} 2$, R5, and R7. A previous study reported significant increases in the skin elasticity parameters R2 and R7 after 90 days of $A$. vera gel powder (1.2 g) intake [18]. Similarly, the results of the present study revealed that dietary supplementation of $0.5 \mathrm{~g}$ of $A$. vera gel powder, containing $40 \mu \mathrm{g}$ of Aloe sterol, increased the skin parameters R2, R5, R7, and F3 (Fig. 2; Table 3). These results suggested that oral administration of $A$. vera gel was beneficial to skin elasticity.

Decreased skin elasticity results in greater fatigue of old skin than young skin, and the F3 parameter is a good marker of skin fragility and aging $[26,27]$. The increase in the F3 value after Aloe sterol intake (Fig. 2; Table 3) suggests improvement in the prevention of aging and fragility of skin tissue. COL1A1 and COL3A1 are key enzymes responsible for collagen. COL1A1 produces a component of type I collagen, whereas COL $3 \mathrm{~A} 1$ produces a component of type III collagen. The results of our previous study confirmed that Aloe sterols promote the production of collagen and increase the expression level of genes involved in the synthesis of type I and type III collagen in human dermal fibroblasts [17]. These results indicate that Aloe sterol affects skin elasticity by promoting collagen production. Nonetheless, further studies are required to examine the effects and elucidate the underlying mechanisms of Aloe sterol on the physical properties of skin.

In this study, we examined the condition of the dermis using noninvasive ultrasonic measurement. The mechanical principle of the DermaLab is dependent on a super- sonic wave, which has the advantage of noninvasive analysis of the skin structure. Gniadecka and Jemec [28] reported that dermal echogenicity is valuable for in vivo study of chronological aging and photoaging. Previous studies have indicated that the increase in the number of LEB is correlated with biological skin aging [29] and sunexposed body sites [30]. Moreover, histological analysis of photoaging in an animal model has suggested that solar elastosis causes, at least in part, an increase in the number of LEB [31]. An increase in the number of LEB was observed in both the Aloe sterol and the placebo groups (Fig. 4a). In this study, each subject was instructed to discontinue the use of cosmetics, including sunscreen, at the measurement site (forearm) during the test period. UV rays cause premature aging of the skin. The characteristic features of photodamaged skin are dry and sallow skin with wrinkles, which are caused by dysregulation of the epidermal and dermal components [32]. Thus, denaturation of collagen fibers using UV might cause an increase in LEB area and decreased TEWL levels.

Skin elasticity is an important marker of skin aging and overall condition. A reduction in skin collagen content is correlated with a decrease in skin elasticity and an increased risk of skin fragility. Moreover, collagen fibers are fragmented by exposure to UV light and/or aging [33]. In the placebo group, the collagen score of the ultrasound image gradually decreased during the test period (Fig. 4b). It is likely that damage to the measurement site caused by daily exposure to UV may be a reason for these results. In contrast, ultrasound imaging revealed that increased light intensity was correlated with collagen density in the Aloe sterol group (Fig. 4b). There were statistical differences in collagen scores at 4,8 , and 12 weeks 
between the Aloe sterol and placebo groups (Table 4). Cho et al. [18] performed immunostaining and RT-PCR analyses of the buttock skin of Korean women before and after $A$. vera gel powder intake. They suggested that ingestion of $A$. vera gel powder increases the type 1 procollagen content in human skin tissue. Also, Aloe sterol promotes collagen production and increases the synthesis of type I and III collagen in human dermal fibroblast [18]. Our preliminary data indicated that ingested Aloe sterol reached the peripheral tissues through the bloodstream [34]. Therefore, it is likely that the collagen content of the dermis was increased via Aloe sterol stimulation of fibroblast cells. Histologic examination of skin biopsy samples was conducted to directly analyze the influence of Aloe sterol on skin, and future additional examination is expected.

The results of this double-blind clinical trial demonstrated that daily oral intake of $40 \mu \mathrm{g}$ of Aloe sterol significantly increased skin barrier function, skin moisture, and skin elasticity. Furthermore, ultrasonographic results suggested that intake of Aloe sterol increased skin elasticity by increasing the collagen content in the dermis. Further histological analysis is needed to elucidate the underlying mechanisms of the effects of Aloe sterol intake on skin health.

\section{Statement of Ethics}

The study protocol was examined and approved by the institutional review board of the Ceravi Shinbashi Clinic in Tokyo, Japan, and it was conducted in accordance with the tenets of the Declaration of Helsinki (2013). All participants provided written informed consent and were free to withdraw from this study at any time.

\section{Disclosure Statement}

There are no conflicts of interests to declare.

\section{References}

1 Calleja-Agius J, Brincat M, Borg M: Skin connective tissue and ageing. Best Pract Res Clin Obstet Gynaecol 2013;27:727-740.

2 Baumann L: Skin ageing and its treatment. J Pathol 2007;211:241-251.

-3 Liu X, Wu H, Byrne M, Krane S, Jaenisch R: Type III collagen is crucial for collagen I fibrillogenesis and for normal cardiovascular development. Proc Natl Acad Sci USA 1997; 94:1852-1856.

4 Varani J, Dame MK, Rittie L, Fligiel SE, Kang S, Fisher GJ, Voorhees JJ: Decreased collagen production in chronologically aged skin: roles of age-dependent alteration in fibroblast function and defective mechanical stimulation. Am J Pathol 2006;168:1861-1868.

5 Farage MA, Miller KW, Berardesca E, Maibach HI: Clinical implications of aging skin: cutaneous disorders in the elderly. Am J Clin Dermatol 2009;10:73-86.

-6 Koyano Y, Nakagami G, Iizaka S, Minematsu T, Noguchi H, Tamai N, Mugita Y, Kitamura A, Tabata K, Abe M, Murayama R, Sugama J, Sanada H: Exploring the prevalence of skin tears and skin properties related to skin tears in elderly patients at a long-term medical facility in Japan. Int Wound J 2016;13:189-197.

7 Shelton RM: Aloe vera: its chemical and therapeutic properties. Int J Dermatol 1991;30: 679-683.

8 Vogler BK, Ernst E: Aloe vera: a systematic review of its clinical effectiveness. $\mathrm{Br} \mathrm{J}$ Gen Pract 1999;49:823-828.
-9 Tanaka M, Misawa E, Ito Y, Habara N, Nomaguchi K, Yamada M, Toida T, Hayasawa $\mathrm{H}$, Takase M, Inagaki M, Higuchi R: Identification of five phytosterols from Aloe vera gel as anti-diabetic compounds. Biol Pharm Bull 2006;29:1418-1422.

10 Nomaguchi K, Tanaka M, Misawa E, Yamada M, Toida T, Iwatsuki K, Goto T, Kawada T: Aloe vera phytosterols act as ligands for PPAR and improve the expression levels of PPAR target genes in the livers of mice with dietinduced obesity. Obes Res Clin Pract 2011;5: 190-201.

11 Chinetti G, Fruchart JC, Staels B: Peroxisome proliferator-activated receptors (PPARs): nuclear receptors at the crossroads between lipid metabolism and inflammation. Inflamm Res 2000;49:497-505.

12 Barlaka E, Görbe A, Gáspár R, Pálóczi J, Ferdinandy P, Lazou A: Activation of PPAR $\beta / \delta$ protects cardiac myocytes from oxidative stress-induced apoptosis by suppressing generation of reactive oxygen/nitrogen species and expression of matrix metalloproteinases. Pharmacol Res 2015;95-96:102-110.

13 Saito M, Tanaka M, Misawa E, Yao R, Nabeshima K, Yamauchi K, Abe F, Yamamoto Y, Furukawa F: Oral administration of Aloe vera gel powder prevents UVB-induced decrease in skin elasticity via suppression of overexpression of MMPs in hairless mice. Biosci Biotechnol Biochem 2016;80:1416-1424.
14 Xia Q, Yin JJ, Fu PP, Boudreau MD: Photoirradiation of Aloe vera by UVA - formation of free radicals, singlet oxygen, superoxide, and induction of lipid peroxidation. Toxicol Lett 2007;168:165-175.

15 Chithra P, Sajithlal GB, Chandrakasan G: Influence of Aloe vera on the healing of dermal wounds in diabetic rats. J Ethnopharmacol 1998;59:195-201.

16 Oryan AT, Naeini A, Nikahval B, Gorjia E: Effect of aqueous extract of Aloe vera on experimental cutaneous wound healing in rat. Vet Arch 2010;80:509-522.

17 Tanaka M, Misawa E, Yamauchi K, Abe F, Ishizaki C: Effects of plant sterols derived from Aloe vera gel on human dermal fibroblasts in vitro and on skin condition in Japanese women. Clin Cosmet Investig Dermatol 2015;895-104.

18 Cho S, Lee S, Lee M-J, Lee DH, Won C-H, Kim SM, Chung JH: Dietary Aloe vera supplementation improves facial wrinkles and elasticity and it increases the type 1 procollagen gene expression in human skin in vivo. Ann Dermatol 2009;21:6-11.

19 Tzellos TG, Klagas I, Vahtsevanos K, Triaridis S, Printza A, Kyrgidis A, Karakiulakis G, Zouboulis CC, Papakonstantinou E: Extrinsic ageing in the human skin is associated with alterations in the expression of hyaluronic acid and its metabolizing enzymes. Exp Dermatol 2009;18:1028-1035. 
20 Lodén M, Olsson H, Axéll T, Linde YW: Friction, capacitance and transepidermal water loss (TEWL) in dry atopic and normal skin. Br J Dermatol 1992;126:137-141.

21 Hashizume H: Skin aging and dry skin. J Dermatol 2004;31:603-609.

-22 Takema Y, Yorimoto Y, Kawai M, Imokawa G: Age-related changes in the elastic properties and thickness of human facial skin. Br J Dermatol 1994;131:641-648.

23 Dobrev H: Use of Cutometer to assess dermal oedema in erysipelas of the lower legs. Skin Res Technol 1998;4:155-159.

24 Dobrev H: A study of human skin mechanical properties by means of Cutometer. Folia Med 2002;44:5-10.

25 Ryu HS, Joo YH, Kim SO, Park KC, Youn SW: Influence of age and regional differences on skin elasticity as measured by the Cutometer. Skin Res Technol 2008;14:354-358.
26 Dobrev H: Application of Cutometer area parameters for the study of human skin fatigue. Skin Res Technol 2005;11:120-122.

27 Ohshima H, Kinoshita S, Oyobikawa M, Futagawa M, Takiwaki H, Ishiko A, Kanto H: Use of Cutometer area parameters in evaluating age-related changes in the skin elasticity of the cheek. Skin Res Technol 2013;19:e238e242.

28 Gniadecka M, Jemec GB: Quantitative evaluation of chronological ageing and photoageing in vivo: studies on skin echogenicity and thickness. Br J Dermatol 1998;139:815-821.

29 Rigal J, Escoffier C, Querleux B, Faivre B, Agache P, Lévêque JL: Assessment of aging of the human skin by in vivo ultrasonic imaging. J Invest Dermatol 1989;93:621-625.

30 Sandby-Møller J, Wulf HC: Ultrasonographic subepidermal low-echogenic band, dependence of age and body site. Skin Res Technol 2004;10:57-63.
31 Wulf HC, Poulsen T, Davies RE, Urbach F: Narrow-band UV radiation and induction of dermal elastosis and skin cancer. Photodermatol 1989;6:44-51.

32 Gilchrest BA, Yaar M: Ageing and photoageing of the skin observations at the cellular and molecular level. Br J Dermatol 1992;127:2530.

33 Fligiel SE, Varani J, Datta SC, Kang S, Fisher GJ, Voorhees JJ: Collagen degradation in aged/photodamaged skin in vivo and after exposure to matrix metalloproteinase- 1 in vitro. J Invest Dermatol 2003;120:842-848.

34 Ishikawa F, Inoue N, Ikeda I, Tanaka M, Yamada $\mathrm{M}$ : Internal accumulation of the plant sterol derived from the aloe in the rat. 49th Annu Meet Jpn Oil Chem Soc, Hakodate, 2010, p 180. 